\title{
Las prácticas artísticas con enfoques feministas como experiencias educativas que promueven la transformación social'
}

\author{
The Artistic Practices With Feminist Approaches As Educational Experiences That Promote \\ Social Transformation ${ }^{2}$
}

\section{Práticas artísticas com abordagens feministas como experiências educacionais que promovem a transformação social ${ }^{3}$}
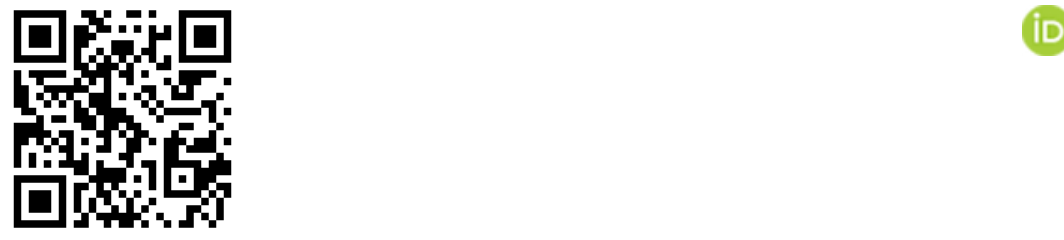

rosario.garcia-huidobro@ulagos.cl

https://orcid.org/0000-0002-1401-9437

Catalina Montenegro-González

Universidad de Los Lagos

Puerto Montt, Chile

catalina.montenegro@ulagos.cl

https://orcid.org/0000-0002-4432-5582

Recibido • Received • Recebido: 06 / 02 / 2018

Corregido • Revised • Revisado: 04 / 06 / 2019

Aceptado • Accepted • Aprovado: 13 / $11 / 2019$

${ }^{1}$ El presente artículo guarda el anonimato de las estudiantes participantes y cuenta con sus autorizaciones para compartir imágenes, experiencias y relatos. Esta autorización se encuentra en los archivos de la revista.

2 This article keeps the participating students' anonymity and has their authorization to share their images, experiences and stories. This authorization is kept in Revista Electrónica Educare processed articles archives.

${ }^{3}$ Este artigo mantém o anonimato dos alunos participantes e tem suas autorizações para compartilhar imagens, experiências e histórias. Esta autorização está nos arquivos da revista. 
doi: http://doi.org/10.15359/ree.24-1.23

URL: http://www.una.ac.cr/educare

CORREO: educare@una.cr

Resumen: El presente artículo busca describir las prácticas artísticas que incorporan una mirada feminista en la formación inicial y reflexionar sobre cómo dicho estudiantado realiza vínculos entre las artes, la enseñanza y el pensamiento feminista, como un aporte para su desarrollo profesional y el del estudiantado en la escuela. Para ello se recoge la experiencia de aprendizaje de un grupo de estudiantes de la carrera de Pedagogía en Educación Artística, de la Universidad Católica Silva Henríquez, quienes durante el curso Taller Creativo Integral realizaron trabajos de creación artística con enfoques feministas y vincularon sus obras con actividades didácticas que ponían en juego aspectos de género y de transformación social en el aula. Postulamos que el tránsito entre lo artístico y lo pedagógico que aprenden en la formación universitaria permite el desarrollo de un compromiso político como artistas-educadores-educadoras, que muestra otros modos de enseñar las artes en el aula, donde evidencian una postura feminista de la educación y de las relaciones pedagógicas. Estos principios nos acercarían a enseñanzas que ponen la práctica artística a favor de experiencias transformadoras, que van más allá del currículo escolar para abrir espacios de diálogo y de comprensión en la escuela.

Palabras claves: Actividades artísticas; educación artística; movimiento feminista; curso de formación.

Abstract: The present article seeks to describe artistic practices that incorporate a feminist perspective in initial university formation and to reflect on how students make links between arts, teaching, and feminist thought as a contribution to their professional development and that of the students at school. For this, the learning experience of a group of students from the career of Pedagogy in Art Education, at Silva Henríquez Catholic University, is collected. During the Integral Workshop course, they carried out works of artistic creation with a feminist approach and linked their works with didactic activities involving gender and social transformation aspects in the classroom. We postulate that the transit between the artistic and the pedagogical fields that they study in the university formation allows the development of a political commitment as artists-educators. This commitment shows other ways of teaching arts in the classroom, where they demonstrate a feminist position of education and pedagogical relationships. These principles would bring us closer to teachings that make the artistic practice adopt a stand in favor of transformative experiences, which go beyond the school curriculum to open spaces for dialogue and understanding in school.

Keywords: Artistic activities; artistic education; feminist movement; training course.

Resumo: Este artigo procura descrever as práticas artísticas que incorporam uma perspectiva feminista na formação inicial e refletir sobre como o referido grupo de estudantes estabelece vínculos entre as artes, 0 ensino e o pensamento feminista, como contribuição ao seu desenvolvimento profissional e do grupo de estudantes na escola. Para isso, recolhe-se a experiência de aprendizagem de um grupo de estudantes da carreira de Pedagogia da Educação Artística da Universidade Católica Silva Henríquez, os quais, durante o curso do Workshop Criativo Integral, realizaram trabalhos de criação artística com abordagens feministas e vincularam seus trabalhos a atividades didática que põe em jogo aspectos de gênero e transformação social na sala de aula. Postulamos que o trânsito entre o artístico e o pedagógico aprendido no ensino universitário permite o desenvolvimento de um compromisso político como artistas-educadoreseducadores, o que mostra outras formas de ensinar artes na sala de aula, onde demonstram uma posição feminista da educação e das relações pedagógicas. Esses princípios nos aproximam de ensinamentos que colocam a prática artística em favor de experiências transformadoras, que vão além do currículo escolar e abrem espaços de diálogo e compreensão na escola.

Palavras-chave: Atividades artísticas; educação artística; movimento feminista; curso de formação. 


\section{Introducción}

Durante el 2017, en la carrera de Pedagogía en Educación artística de la Universidad Católica Silva Henríquez, desarrollamos el curso Taller Creativo Integral. Esta fue una asignatura práctica, que buscó promover en el estudiantado una línea de investigación creativa que les permitió preparar su bagaje crítico-reflexivo entorno a las artes y la docencia. En esta asignatura, además de desarrollar trabajos y experiencias artísticas, era importante que al presentar su contenido y proceso de creación, también la situaran en un espacio pedagógico. Esto lo desarrollaban al responder preguntas como: ¿Qué actividad pedagógica podrías crear desde este trabajo artístico? ¿Qué contenido podrías desarrollar? ¿Con estudiantes de qué año podrías realizar esta actividad? De esta manera, las personas artistas-docentes en formación desarrollaban un quehacer artístico que no se desvinculaba del compromiso educativo (García-Huidobro, 2018) e iban aprendiendo que los artistas y las artistas más que actuar como individuos son una posición (Velasco, 2015) y más que ser inventores son mediadores de la vida social. Por ende, en este curso, la práctica artística no buscaba defender la autonomía del arte, sino desarrollar un sentido político, donde la experiencia transformativa era esencial (Collados y Rodrigo, 2015).

Otro aspecto relevante del curso fue promover que el estudiantado pudiera crear actividades pedagógicas que surgieran de sus intereses y creaciones artísticas (García-Huidobro, 2016) y, desde ese lugar onto-epistemológico (Barad, 2003), invitarles a pensarse como artistasdocentes de manera conjunta y no aislada (Daichendt, 2010). Asimismo, nos situamos para entender la noción artista-docente como quien es artista y profesor o profesora al mismo tiempo, sin separar modos de ser y de hacer (Daichendt, 2010). Entender al profesorado de artes desde este posicionamiento es una apertura que nos ayuda a identificar los múltiples cruces entre las acciones del arte y de la enseñanza.

Para dar cuenta de este relato, en este artículo nos proponemos describir las prácticas artísticas que incorporan una mirada feminista en la formación inicial docente y reflexionar sobre cómo dicho estudiantado realiza vínculos entre las artes, la enseñanza y el pensamiento feminista, como un aporte para su desarrollo profesional y el del estudiantado en la escuela. Para explicar ello, nos situaremos en la experiencia de un grupo de mujeres del curso Taller Creativo. Pensamos relevante compartir los trabajos artísticos de este curso y, además, las actividades pedagógicas que pensaron para dichas creaciones, ya que las gestaron desde intereses y preocupaciones que las implicaba como mujeres. Tras esta idea, podemos desvelar que los trabajos presentados por las estudiantes buscaron visibilizar injusticias y discriminaciones ante el género femenino en Chile y cuestionar cómo un determinado cuerpo -y con características cruzadas por el sexo, clase, raza, edad, época, etc.- restringe posibilidades de ser y saber (Butler, 2007), desde este lugar donde sus propuestas creativas se vinculaban con experiencias artísticas feministas, donde el compartir sus experiencias vividas como mujeres fueron el centro de la creación. Esto permitió develar ciertas problemáticas entorno al género que situaron a sus creaciones como manifestaciones artísticas-políticas. 
doi: http://doi.org/10.15359/ree.24-1.23

URL: http://www.una.ac.cr/educare

CORREO: educare@una.cr

Es importante precisar que no clasificaremos sus trabajos como manifestaciones de arte feminista, sino como experiencias que se vinculan con las prácticas artísticas feministas. Subrayamos esta idea porque en el ámbito de las artes, "la producción de mujeres no es necesariamente producción feminista y habrá que evaluar el costo que ha tenido el esencialismo en estas propuestas, principalmente para nuestro cuerpo (colectivo universal) pero también para invención de la estética femenina" (Cares, 2017, p. 115). Antes de comentar algunos trabajos realizados por las estudiantes del curso Taller Creativo, revisaremos ideas sobre las prácticas artísticas feministas y las líneas educativas que siguen enfoques feministas.

\section{Prácticas artísticas feministas}

A partir de los años setenta, la consigna nuestros cuerpos, nosotras cobró relevancia en todas las disciplinas en las que un grupo de mujeres estuviera presente. Desde aquí las mujeres comenzaron a hacer de sus cuerpos un lugar donde (re)inscribir nuevos significados, cuestionando los arquetipos de lo femenino, para situar una nueva política del cuerpo que, en las artes plásticas y visuales, abrió paso a otras formas culturales de pensarse y expresarse. Estas pusieron en el centro la experiencia de saberse cuerpo, un lugar para re-significar los significados del imaginario femenino desde la experiencia personal (Martínez-Collado, 2014).

Es importante mencionar que antes de los años 70, también encontramos una larga genealogía de maestras artistas (Grosenick, 2005; Reilly, 2015), quienes a pesar de las limitaciones culturales (Nochlin, 1971), estuvieron trabajando con el cuerpo y dotándolo de significado simbólico, poniendo en juego sus experiencias artísticas para explorar y cuestionar el sentido de saberse cuerpo.

Desde que comenzaron los diversos movimientos feministas a fines de los sesenta, la temática del cuerpo tomó mayor fuerza. En el arte, el cuerpo dejó de ser idealizado, admirado y tratado como objeto de deseo y se transformó en un proyecto de exploración personal y político en primera persona. Se transformó en un material artístico para explorar la realidad personal y social de las mujeres. A partir de esta re-significación, muchas comenzaron a explorar y reflexionar nuevas posibilidades de la realidad femenina, desde diversas prácticas artísticas. Así el cuerpo, para algunas artistas se transformó en campos de batalla, en espacios de resistencia y un lugar para cuestionar las prácticas institucionales represivas que oprimían a las mujeres de la época. También, para otras artistas, el cuerpo se transformó en nuevas instancias de re-significación, transformando su hacer en libertad femenina y un lugar para recolocar el deseo de ser como afirmación.

Desde los años setenta que algunas artistas como Cindy Sherman (EE.UU.), Ana Mendieta (Cuba), Yolanda López (México), Jenny Saville (Reino Unido), Esther Ferrer (España) Ahn Sun Mi (Corea del Sur), entre muchas otras, han "dado un paso más allá del autorretrato utilizando la autorrepresentación como forma de expresión artística" (Valdivieso, 1994, p. 108). Esto ha sido 
una manera política de dar cuenta de que la experiencia femenina en las artes explora aspectos vinculados a la identidad y la subjetividad, cuestionando y deconstruyendo los cánones tradicionales de lo que es arte y de lo que es una experiencia femenina en las artes.

\section{Prácticas feministas en educación}

Las pedagogías feministas y las prácticas en contextos educativos, como señalan Belausteguigoitia y Mingo (1999), nacen desde el descontento de ver cómo el patriarcado presenta situaciones de privilegio y situaciones de control sobre las mujeres y se apoderaba de los procesos de escolarización, manteniendo y reproduciendo discursos masculinistas. Por lo anterior, las pedagogías feministas se presentan como un discurso que contextualiza y orienta la educación, es ella la"que sustenta y promueve la ética y un objetivo político, y que como tal, es una herramienta indispensable para el trabajo y avance del feminismo" (Ochoa, 2008, p. 28). En este sentido, entonces, hablar de un discurso pedagógico es hablar también de un posicionamiento que, en el caso de las pedagogías feministas, se plantea desde la "distancia con el patriarcado y en actitud propositiva, colaborativa e integradora, logrando formas de ver las pedagogías que no se limitan al quehacer de las escuelas formales" (Montenegro, 2015, p. 226). Con esto, las pedagogías feministas pueden ser pensadas en sentidos más amplios que permean la escuela "haciéndose hincapié en la forma de producirse el conocimiento y la experiencia marcados por el género" (Gore, 1996, p. 46). Según las evidencias, en las pedagogías feministas existen puntos en común entre las diferentes corrientes de pensamiento, ya sea desde los feminismos radicales, liberales, estudios de la diferencia sexual, desde los estudios de la mujer o desde la pedagogía y es que se reconoce que "las pedagogías feministas están necesariamente contextualizadas a momentos y lugares determinados" (Montenegro, 2015, p. 229). Por lo tanto, mantendrán como aspecto central el contexto y las propias experiencias para la construcción del conocimiento. Esto implica ser constantemente críticas con los medios educativos formales y las relaciones con movimientos y pedagogías feministas para ser respetuosas con las características del momento.

Jennifer Gore reafirma las ideas de Giroux señalando que "tanto los discursos pedagógicos críticos como los feministas hacen hincapié en la experiencia y la voz de los alumnos ... están vinculados con movimientos políticos y sociales que tratan de erradicar las múltiples formas de opresión" (Gore, 1996, p. 25). Por otro lado, las pedagogías feministas no se limitan a las escuelas o espacios de educación superior, sino que pueden ser llevadas a cabo en cualquier contexto y construir espacios de pensamiento. Mientras que para la pedagogía crítica se concentran en los establecimientos educativos y desde ahí a los contextos sociales, las feministas posestructuralistas plantean la idea de que este espacio de pensamiento reflexivo puede ser llevado a cabo en cualquier contexto de la vida cotidiana, valoran, por tanto, todas las experiencias de la vida para aprender y no solo las que se desarrollan en la escuela. Según lo anterior, habrá dos puntos fundamentales al momento de hablar de pedagogía feminista, los 
doi: http://doi.org/10.15359/ree.24-1.23

URL: http://www.una.ac.cr/educare

CORREO: educare@una.cr

cuales hacen referencia a "experiencia y contexto. Pensando [en] las personas como un todo y no potenciando exclusivamente los procesos cognitivos" (Montenegro, 2017, p. 414).

\section{Experiencias artísticas y pedagógicas con enfoques feministas en la formación inicial docente}

A continuación, compartiremos algunas obras realizadas por las estudiantes del curso Taller Creativo y reflexionaremos cómo se vinculan con las prácticas artísticas feministas y también cómo el tipo de actividad pedagógica derivado de su trabajo creativo promueve ideas que involucran a la pedagogía feminista. El cruce entre ambas prácticas feministas nos permitiría hablar de trabajos que corporizan y apuntan hacia lo político en la educación de las artes y a la transformación social.

\section{Prácticas artísticas-pedagógicas y violencia contra las mujeres}

Comenzaremos comentando el trabajo de una estudiante titulado Palabras implícitas (véase Figura 1). Este consistió en una serie de cinco fotografías que representaban partes del cuerpo femenino y que llevaban tatuadas frases, tales como: loca, fea, tonta y no vales nada.

Para hablar de su trabajo la estudiante expresó:

Todas las mujeres han sido víctimas verbalmente en algún momento, pero estas agresiones no dejan marcas físicas, de ahí la creación de palabras implícita, en donde se visibiliza este ataque de insultos, a través de marcas explícitas en la piel, de frases que lastiman nuestra mente y autoestima. (Relato de estudiante)
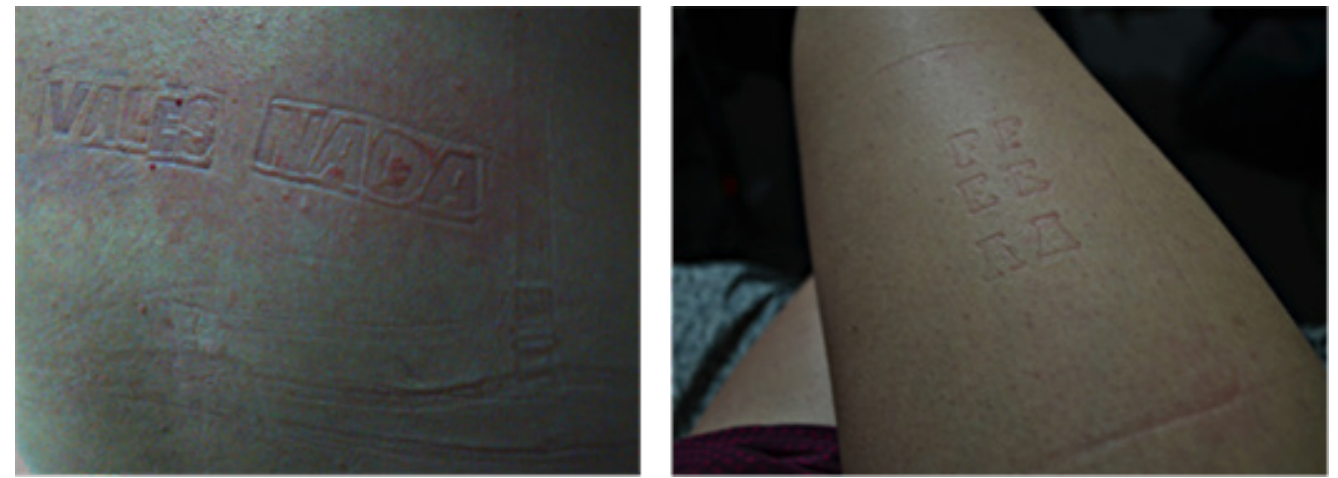

Figura 1: Detalle trabajo "Palabras implícitas", fotografía sobre papel, 10x15 cm. cada una. Nota: Elaboración de estudiante de la Universidad Católica Silva Henríquez. Se reproduce con autorización. 
Como se aprecia en su trabajo artístico, la estudiante busca visibilizar y cuestionar cómo la violencia de género verbal es una conducta normalizada socialmente. Al tatuar esas palabras en la piel de las mujeres fotografiadas, además de visibilizar una realidad escondida (Red Chilena contra la Violencia Doméstica y Sexual, 2016), realiza un Ilamado de concienciación para detectar esas realidades marginadas, aspectos que han tenido cada vez mayor relevancia a partir de los movimientos feministas de 2018 en Chile y que han removido el lugar de la hegemonía en los espacios de aprendizaje formal, como las universidades o las escuelas. Para vincular este trabajo con las prácticas feministas y los acontecimientos sociales, rescatamos a Mónica Mayer (Villegas, 2019), quien sostiene que el arte feminista es un movimiento político, creado y formado por mujeres artistas que se han interesado por participar, en el área de la cultura y las artes, de tres maneras. Primero, promoviendo el trabajo creativo de mujeres artistas, ya sea rescatando a las artistas olvidadas o visibilizando los derechos y creaciones de estas profesionales del arte a lo largo de la historia. En segundo lugar, visibilizando y valorando temáticas relacionadas con búsquedas feministas, como también criticar las nociones patriarcales que limitan a las mujeres. Por último, incidir en el imaginario social cuestionando la imagen sexista que se ha mostrado de las mujeres para modificarla y mostrar nuevas formas de vivirse como mujeres en libertad.

Respecto a estas visiones, podemos señalar que el trabajo de la artista-docente se vincula prioritariamente con el segundo punto, ya que en su creación artística busca visibilizar una realidad de violencia que se ha regularizado y que las mujeres han asumido como condición (Observatorio de Equidad de Género en Salud, 2013). Por otro lado, la estudiante además de presentar su trabajo artístico compartió una actividad pedagógica que tituló Cuerpo a la venta. La estudiante proyectó la actividad para un curso de séptimo básico y propuso lo siguiente:

Los estudiantes individualmente crearán un afiche publicitario donde el objeto a la venta será su cuerpo ... Deberán agregar caracteres o atributos positivos sobre su personalidad, habilidades o aptitudes, provocando así su óptima comercialización y exposición entre los compañeros. Luego, en conjunto se discutirá sobre lo que significa vender tu cuerpo y reflexionar sobre los rasgos positivos que incrementen la autoestima de cada uno. (Relato de estudiante)

La propuesta pedagógica presentada surge desde el tema de la violencia contra la mujery, desde aspectos publicitarios, nos propone la reflexión de un escenario novedoso en el currículo chileno: la temática del cuerpo no para ser estudiado en cuanto a sus proporciones, sino respecto a su reconocimiento y limitaciones. Esto alcanza coherencia con la propuesta de las bases curriculares de séptimo año, al considerar temáticas de género dentro de las propuestas de sus unidades en concordancia con los objetivos de aprendizaje del nivel que apuntan no solo a la producción artística, sino también a la reflexión de los temas. Esta invitación a la reflexión se vincula con las pedagogías feministas en tanto plantea una crítica distancia del sistema patriarcal y sus alcances en la vida cotidiana, como la publicidad y la imposición de cánones de belleza que cosifican y estereotipan los cuerpos femeninos. Es importante, en este trabajo, la 
doi: http://doi.org/10.15359/ree.24-1.23

URL: http://www.una.ac.cr/educare

CORREO: educare@una.cr

consideración de imágenes de la vida cotidiana y las posibilidades que presenta la propuesta desde la cultura visual como un espacio de análisis y desarrollo del pensamiento crítico más allá del arte visual. Retomando la idea de que es un tema que se propone formalmente por parte del Ministerio de Educación para ser trabajado en la asignatura de artes visuales, es importante considerar la propuesta artística en relación con el maltrato y sus posibles maneras de control no visibles. Consideramos la propuesta como una forma de prevenir estas situaciones en el contexto escolar para desnaturalizar el maltrato hacia las mujeres, aspecto que no se vincula directamente con las espacios de aprendizaje formales, pero que se relaciona con las pedagogías feministas al ser planteamientos que, según Montenegro (2015), permean los espacios de la sociedad y se preocupa de temas no escolares, esto al considerar las experiencias para poder construir conocimiento, que en este caso se materializa en la propuesta presentada.

\section{Prácticas artísticas-pedagógicas y estereotipos}

El segundo trabajo que se comparte fue presentado por una estudiante que realizó una instalación que exhibía la palabra Belleza escrita con cabello (véase Figura 2). En el trabajo, la artista-docente cuestiona la materialidad con la que se ha escrito dicha palabra, para evidenciar de manera metafórica los prototipos de belleza que muestra la sociedad.

El pelo -cuenta la estudiante- en los tiempos de hoy es algo bastante importante ya que de alguna y otra forma, ya sea por la televisión, publicidad, redes sociales o simplemente la concepción de mujer bella, hacen que el pelo sea una cierta identificación femenina. ¿Pero qué pasa con las mujeres que no tienen pelo ya sea por enfermedades o por opción propia? ¿Son menos mujeres que las que sí tienen? (Relato de estudiante)
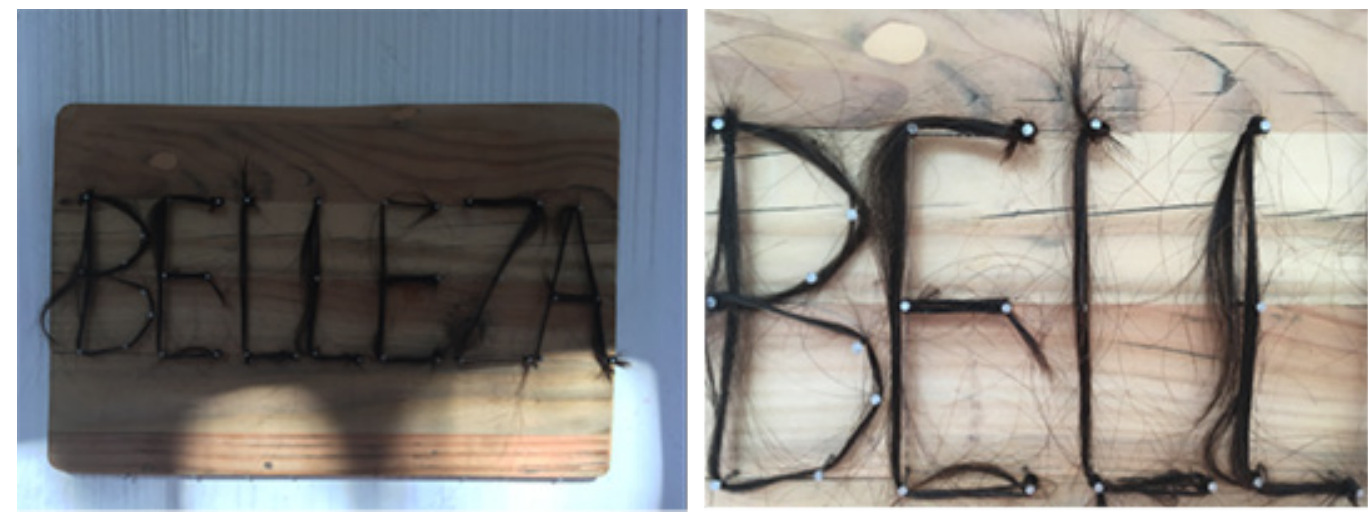

Figura 2: Sin título, pelo, madera y clavos, $40 \times 55 \mathrm{~cm}$.

Nota: Elaboración de estudiante de la Universidad Católica Silva Henríquez. Se reproduce con autorización. 
A partir de su crítica nos invita a reflexionar sobre los cánones de belleza que se han establecido y cómo han generado una normativa ante el uso y estilo de cabello que deben llevar las mujeres para ser aceptadas socialmente (Red Chilena contra la Violencia Doméstica y Sexual, 2016). A su vez, nos hace pensar en cómo esta normalización afecta en la idea impuesta sobre belleza de la mujer y cómo afecta en la autorrealización y autoestimas de ellas. Por otro lado, la artista-docente nos cuenta que,

Este trabajo se desarrolló a partir de mi experiencia personal como mujer y de cómo afectó en mi vida estos supuestos requisitos de mujeres bellas ... Cuando era pequeña sufrí una enfermedad muy desconocida llamada tricotilomanía, es un tic maniaco de arrancarse todo el pelo de diferentes partes del cuerpo consciente e inconscientemente (...) Hace ya 8 años integré a mi vida la peluca que creo que ha sido lo mejor que me ha pasado en la vida me da una seguridad me siento bella. Hoy tengo 26 años y recién puedo decir que me acepto tal cual soy, que en la noche me pongo mi pijama y saco mi peluca sin ningún pudor. (Relato de estudiante)

Como podemos apreciar, su trabajo se vincula con las prácticas feministas desde diversas vertientes. Primero, porque su creación surge de una vivencia personal que la empodera a través del hacer artístico, como un modo reivindicativo de reflexionar su experiencia y de transformar lo personal en un hacer político desde las artes (Martínez-Collado, 2014). Esta idea alude al cómo diversos grupos de mujeres, desde los 70, comenzaron a manifestar sus conflictos personales desde experiencias artísticas, vinculando sus proyectos a la esfera pública y política. Estos trabajos supusieron momentos de toma de conciencia para muchas mujeres y una forma de visibilización que pusieron en el centro la necesidad de contar sus experiencias desde un punto de vista artístico (Cares, 2017; Martínez-Collado, 2014). Por otro lado, a través del juego que hace entre la palabra y su materialidad (belleza-cabello), la artista-docente critica el imaginario social que ha creado el pensamiento logocéntrico, para cuestionar la imagen sexista que se ha mostrado de las mujeres y los cánones estéticos a los cuales tienen que responder. Este tipo de cuestionamiento es propio de los proyectos feministas, al intentar buscar nuevas maneras de vivirse y entender la realidad, al margen de los mensajes patriarcales que constriñen la vida de las mujeres.

Siguiendo esta línea de crítica social, la artista-docente en formación nos comparte una actividad pedagógica que busca reflexionar sobre los peligros de la enseñanza sexista en la escuela. Para ello, señala que en su actividad sus estudiantes deben:

... Organizarse en parejas para dibujar sus siluetas y en ellas trazar los modelos de mujer impuesto y compararlos con los que desean ser más allá de los estereotipos. Luego dialogarán con sus compañeros sobre cómo lo viven en la realidad. (Relato de estudiante)

La actividad pedagógica que presenta la artista-docente en formación, surge respecto a su cuestionamiento por los ideales de belleza que la sociedad impone a hombres y mujeres. A través 
doi: http://doi.org/10.15359/ree.24-1.23

URL: http://www.una.ac.cr/educare

CORREO: educare@una.cr

de esta crítica realiza una actividad donde invita al estudiantado a reflexionar y tomar conciencia sobre aquello que los medios y la publicidad nos invitan a ser, contraponiéndolo con aquellas formas simbólicas y representativas de lo que cada chico y chica es o desea ser, al margen de aquellas exigencias. Las enseñanzas feministas buscan no solo que el estudiantado pueda tomar conciencias de esas formas de control, sino que también puedan ser dialogadas en el aula, para que niños y niñas puedan aceptarse en sus diferencias, propiciando también la valoración de esta misma. En su obra se evidencia un proceso reflexivo asociado a su experiencia, propio de las pedagogías feministas y que la lleva a reflexionar sobre su condición de ser mujer y las imposiciones de cánones de belleza que la sociedad la empuja a cumplir. A través de su obra cuestiona los ideales de belleza respecto de ser hombre o mujer y cómo responder a estímulos sociales masculinizados del deber ser a través de su propuesta artística. Se relaciona también con las pedagogías feministas en tanto propicia el espacio para reflexionar sobre la incomodidad de tener que responder a los cánones establecidos, mismo ejercicio que realizan Belauteguigoitia y Mingo (1999) en relación al pensamiento de la pedagogía feminista como respuesta a la sociedad patriarcal y como una forma "del señalamiento de las particularidades de la opresión como de los mecanismos y formas de liberación" (Belausteguigoitia y Mingo, 1999, p. 19).

\section{Prácticas artísticas-pedagógicas e historia personal}

El tercer y último trabajo que se comparte fue titulado por la estudiante ¿Y tu primera vez? (véase Figura 3). Consistió en una instalación compuesta por un volumen de protectores diarios dispersos en el suelo que, en color rojo, tenían escrito la fecha de la primera regla de muchas mujeres. Estos estaban ubicados en un rincón de la Universidad, donde dos puertas abiertas mostraban una gran toalla higiénica pegada al muro.

Según la artista-docente en formación, la apertura de puertas actuaba como metáfora para señalar la abertura de estas mujeres que quisieron visibilizar aquello que en nuestra sociedad es oculto: la menstruación femenina. El origen de este trabajo surge de la primera menstruación de la estudiante, quien reveló que "fue una experiencia que marcó un antes y un después en mi vida, tanto en lo social por el hecho de ya ser una señorita, como en lo personal por todas las condiciones en que esto ocurrió" (Relato escrito de la estudiante). Según lo acontecido, la estudiante reveló que el día en que llegó su primera menstruación, su madre reveló dicho suceso a todos los familiares, quedando expuesta la intimidad de la estudiante, suceso que causó en ella extrañeza. En base a ello, la estudiante cuenta:

Esta experiencia hizo que mi vida cambiara completamente, ese 23 de diciembre del 2004 entre en la pubertad, y yo me pregunto: ¿los hombres recuerdan cuando entraron en la pubertad? (Relato de estudiante) 

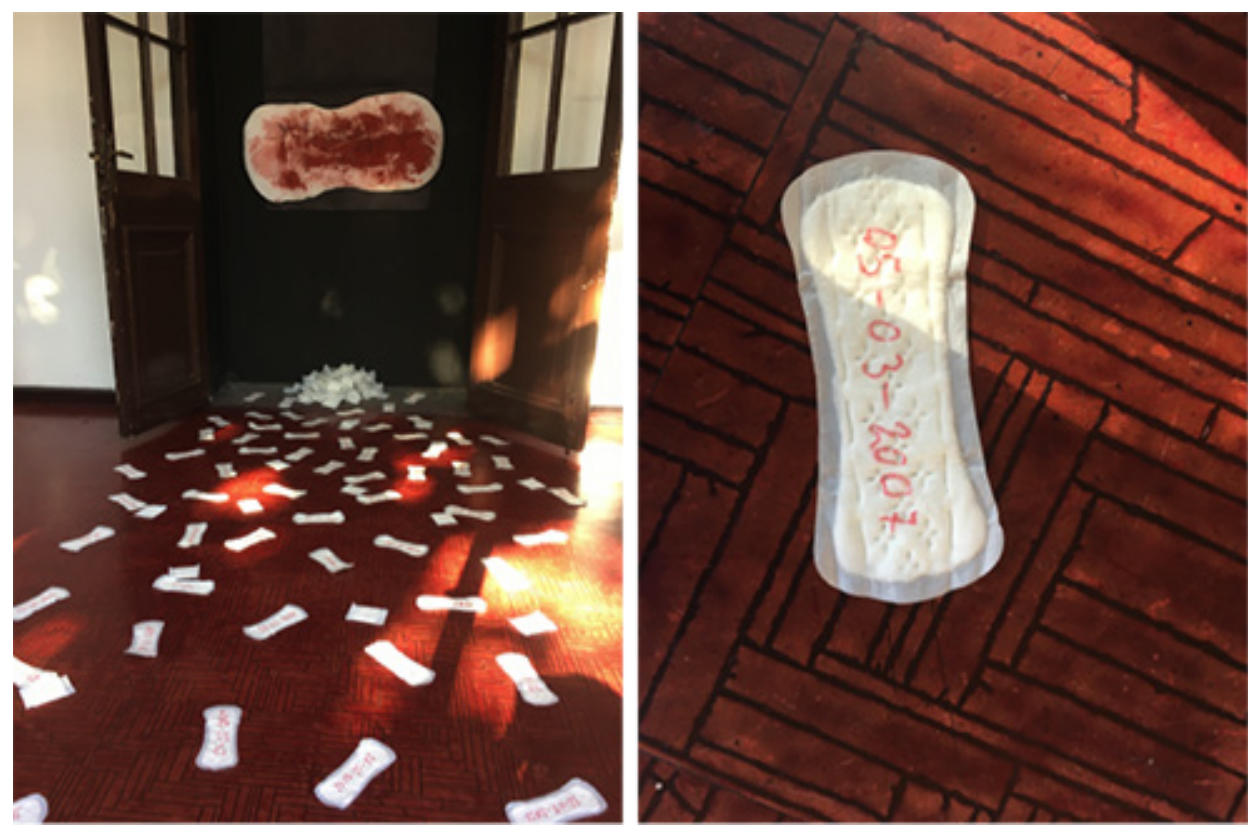

Figura 3: ¿Y tu primera vez? Instalación de protectores diarios intervenidos.

Nota: Elaboración de estudiante de la Universidad Católica Silva Henríquez. Se reproduce con autorización.

Más allá de los datos anecdóticos que acompañan la obra y nos comparte la estudiante, podemos apreciar que su creación artística se enfoca en su historia personal, específicamente en su primera regla. A partir de este hito de transformación en su vida, la estudiante abre esa experiencia para que otras mujeres también puedan contar su historia. Según la artista-docente contó:

Para conseguir las fechas, publiqué este proyecto en las redes sociales, y muchas mujeres respondían hasta con la hora, o con un pequeño resumen de cómo fue ese día. Para algunas fue bueno y para otras muy malo. La idea de esto es que veamos hasta qué punto influye en nosotras los estándares sociales sobre cosas personales, como por ejemplo, que la menstruación debe llegar entre ciertas edades, o que después de ese día debes comportante diferente. (Relato de estudiante).

Es indudable pensar los diversos puntos con que este trabajo se vincula con las prácticas artísticas feministas. En primer lugar, esta creación surge desde la experiencia que la estudiante tuvo con su primera menstruación, lo que nos reafirma la importancia de que las creaciones con enfoques feministas recaten experiencias vividas en torno a lo personal, para reflexionarlas desde lo público. Este tipo de creaciones nos recuerda la serie de trabajos realizados por la artista feminista Tracey Emin, quien desarrolla instalaciones donde hace público sus experiencias amorosas y sexuales. Los trabajos de esta artista inglesa consisten en tomar aspectos de su vida 
doi: http://doi.org/10.15359/ree.24-1.23

URL: http://www.una.ac.cr/educare

CORREO: educare@una.cr

personal para ser convertidos en producto artístico (Sáez, 2015). Sin ir más allá, su obra Everyone I have ever slept with, 1963-1995, se vincula con el trabajo presentado por la artista-docente en formación por el cómo ambas hacen de la experiencia un espacio simbólico. Sobre la obra de Emin, se señala que al traspasar la puerta de la tienda de campaña se ingresa a un lugar sagrado, un santuario. Del mismo modo, la metáfora que la estudiante nos propone al mostrar puertas abiertas es señalarnos la apertura de un lugar simbólico para muchas mujeres, quienes han dejado por escrito un dato importante en sus vidas.

También podemos vincular el trabajo de la estudiante con las prácticas feministas porque es un proyecto abierto que involucra y visibiliza la experiencia de otras mujeres, un llamado que el pensamiento feminista realiza desde los setenta al buscar espacios que permitan compartir experiencias y escucharse entre mujeres (Rivera, 2001). El trabajo visibiliza aquella experiencia femenina que se oculta, articulándose como un homenaje al cuerpo de muchas mujeres y un llamado a hablar.

Por último, pensamos que este trabajo se vincula con aspectos feministas porque, como señala López Fernández (1991-1992), muchas artistas de los años ochenta buscaron revertir los signos de dominación desde estrategias irónicas, por ejemplo, empleando un lenguaje dominante, pero contradiciéndolo a la vez. Así, la instalación de la artista-docente utiliza el protector diario como elemento impuesto y normalizado en la cultura dominante, para sacar a luz cómo la menstruación es una experiencia que en la vida cotidiana de las mujeres se enseña a ocultar y que, además, se enseña como la construcción de la femineidad (Guillo, 2013). Aquella experiencia femenina de menstruar, que ha sido normada y silenciada, en el trabajo de la estudiante se visibiliza y se interviene con una escritura que demarca la fechas de primera regla, como una forma de empoderar el cuerpo femenino.

Por otro lado, también merece la pena reflexionar la actividad pedagógica que presenta la artista-docente en formación, quien nos propone que en un primero medio,

Los estudiantes realicen investigaciones artísticas y creen trabajos visuales utilizando los medios de expresión de grabado y libro de artista. ... El objetivo es reflexionar en torno a un hito que sientan que marcó sus vidas con un antes y un después, ya sea social o personalmente. (Relato de estudiante)

Podemos apreciar que la estudiante traslada la idea de su trabajo artístico sobre los hitos personales y sociales al ámbito pedagógico y realiza un llamado para que el estudiantado pueda reflexionar y tomar conciencia de aquellos aspectos o situaciones que han conformado su realidad. Esto es interesante porque hace una invitación al estudiantado en un espacio donde no es habitual este tipo de propuestas y donde el objetivo del trabajo está puesto en un proceso reflexivo más que en la creación de un artefacto visual o producto para ser evaluado. De esta manera, existe una consideración y relevancia fundamental en los propios relatos estudiantiles

12 Rosario García-Huidobro-Munita y Catalina Montenegro-González

Los artículos de la Revista Electrónica Educare del Centro de Investigación y Docencia en Educación de la Universidad Nacional, Costa Rica, se comparten bajo términos de la Licencia Creative Commons: Reconocimiento, № Comercial, Sin Obra Derivada 3.0 Costa Rica. Las autorizaciones adicionales a las aquí delimitadas se pueden obtener en el correo: educare@una.cr 
respecto a la propuesta en relación con sus espacios personales y sociales. Así se vincula la propuesta de la estudiante al considerar las propias trayectorias de vida para realizar las reflexiones e invita a empoderarse de los espacios escolares por las propias personas escolares a través de la evocación de sus experiencias. Esto nuevamente se vincula con las pedagogías feministas al dar espacio a los relatos personales y al partir de sí que propone Piussi (2000). Es interesante también plantear la posibilidad de la construcción del conocimiento a partir de experiencias colectivas que permiten abrir los debates hacia aspectos comunes de experiencias adolescentes, pero que permiten visibilizar las singularidades de las experiencias particulares "reconocimiento de la diversidad de puntos de vista en la perspectiva de la educación para la comprensión" (Hernández, 2010, p. 41).

\section{Conclusiones}

Las propuestas tienen como puntos centrales los principios de las prácticas artísticas feministas y las pedagogías feministas, tales como experiencia, contexto o partir de sí (Piussi, 2000), las cuales se articulan para dar sentido desde procesos reflexivos y espacios para la construcción de identidad, tanto de las profesoras en formación como del estudiantado que eventualmente podría llevar a cabo estas actividades en contextos escolares formales. Así, el vínculo entre las creaciones artísticas y las actividades pedagógicas que desarrollan estas artistasdocentes en formación son iniciativas necesarias para el ámbito de las artes y el educativo, dadas las constantes discusiones en torno a la condición de mujer, docente y feminista en el ámbito educativo y que va tomando mayor fuerza con las movilizaciones sociales en Chile, donde cada vez tienen mayor visibilidad las demandas vinculadas a las problemáticas femeninas, que ponen en discusión las relaciones de poder y control hacia las mujeres.

Son relevantes para el área artística porque muestran realidades diversas, visibilizan aspectos cruciales de la vida de las mujeres desde lenguajes que nos despiertan conciencia y nos movilizan políticamente. Además, estos procesos creativos se organizan no solo como obra, sino también como proceso reflexivo-crítico. También son creaciones que, en el contexto donde se realizan, remueve a otras y otros artistas-docentes en formación, profesorado y personal de la institución; abren espacios de diálogo y promueven el cuestionamiento sobre esta realidad. En este sentido, el trabajo realizado no son solo proyectos artísticos, sino también un lugar de reflexión social.

De este modo, hablamos de una política artística (García-Huidobro, 2017) que promueve la transformación social, en el sentido que no es ajena a lo que nos pasa en cuanto a aspectos de género. Braidotti (2000) ha señalado que para hacer política es necesario establecer una visión ontológica del sujeto, lo que implica valorar como punto de partida la experiencia de quienes la ejercen. En este caso hablamos de prácticas que desarrollan mujeres, artistas y docentes en formación, desde las cuales se busca una resistencia a las formas hegemónicas que se expresan tanto en la vida de las mujeres, como en las prácticas artísticas y aquellas insertas en ámbitos 
doi: http://doi.org/10.15359/ree.24-1.23

URL: http://www.una.ac.cr/educare

CORREO: educare@una.cr

pedagógicos, lo que se transforma en una invitación para las participantes en tanto crítica de los espacios de aprendizaje hegemónicos en los que se verán envueltas al momento de ejercer la profesión como artistas y docentes.

En este sentido, llevar estas creaciones al ámbito escolary promover actividades pedagógicas que visibilicen y cuestionen la realidad de las mujeres en diálogo con el currículo escolar que emana del Ministerio de Educación chileno, responde a un llamado social que atañe al vivirse tanto como mujer, artista y docente, porque estas tres figuras están fundadas y cruzadas por aspectos políticos. Es desde aquí donde apostamos un doble compromiso político de las artistasdocentes en formación, quienes, a través de sus creaciones artísticas y pedagógicas, promueven espacios alternativos en torno a las artes, que permiten nuevas posibilidades de transformación.

Al mismo tiempo abren nuevas miradas en la escuela, favoreciendo el intercambio de conocimiento y las nuevas formas de trabajar que sitúan las artes como un espacio político (Collados y Rodrigo, 2015) y de constante reflexión en torno a las propias prácticas docentes y artísticas en contexto de aprendizaje formales, pero que, sin duda, tienen la posibilidad de posicionarse en cualquier lugar de la sociedad para poder abrir los espacios de diálogo y reflexión crítica a partir de la creación artística.

\section{Referencias}

Barad, K. (2003). Posthumanist performativity: Toward an understanding of how matter comes to matter. Journal of Women in Culture and Society, 28(3), 801-831. doi: https://doi. org/10.1086/345321

Belausteguigoitia, M.y Mingo, A. (1999). Fugaa dos voces. Ritmos, contrapuntosy superposiciones del campo de los estudios de género y la educación En M. Belausteguigoitia y A. Mingo (Eds.), Géneros prófugos. Feminismoyeducación (pp. 13-54) México, D. F.: Paidós. Recuperado de $\quad$ http://kolectivoporoto.cl/wp-content/uploads/2015/11/Varios-G\%C3\%A9nerosPr\%C3\%B3fugos.-Feminismo-y-educaci\%C3\%B3n.pdf

Braidotti, R. (2000). Sujetos nómades. Corporización y diferencia sexual en la teoría feminista contemporánea. Buenos Aires: Paidós.

Butler, J. (2007). El género en disputa. El feminismo y la subversión de la identidad. Barcelona: Paidós.

Cares, C. (2017). Arte, género y discurso. Representaciones sociales en el Chile reciente (Tesis doctoral). Universidad de Barcelona, Barcelona. Recuperado de https://www.tdx.cat/ handle/10803/402144

Collados, A. y Rodrigo, J. (Eds.). (2015). Transductores 3. Prácticas artísticas en contexto. Itinerarios, útiles y estrategias. Granada: Centro José Guerrero. Recuperado de http:// blogcentroguerrero.org/wp-content/uploads/2016/10/Transductores3 online.pdf 
Daichendt, J. (2010). Artist teacher. A philosophy for creating and teaching. Chicago: Intellect.

García-Huidobro, R. (2016). Diálogos, desplazamientos y experiencias del saber pedagógico. Una investigación biográfica narrativa con mujeres artistas-docentes (Tesis doctoral). Universidad de Barcelona, Barcelona. Recuperado de https://www.tdx.cat/handle/10803/396195

García-Huidobro, R. (2017). Retratar a otras mujeres y cartografiar nuestros vínculos. Investigaciones feministas, 8(2), 603-618. doi: https://doi.org/10.5209/INFE.54143

García-Huidobro, R. (2018). Artistas-docentes que aprenden a enseñar. Abriendo espacios pedagógicosy transgrediendo dualidades. Innovacióneducative, 18(77), 39-56. Recuperado de http://www.scielo.org.mx/pdf/ie/v18n77/1665-2673-ie-18-77-39.pdf

Gore, J. M. (1996). Controversias entre las pedagogías. Madrid: Morata.

Grosenick, U. (2005). Women artists: Mujeres artistas de los siglos XXX XXI. Köln: Taschen.

Guillo, M. (2013). La in-corporación de la investigación: Políticas de la menstruación y cuerpos (re)productivos. Nómadas, 39, 233-245. Recuperado de http://www.redalyc.org/articulo. oa?id=105129195016

Hernández, F. (2010). Educación y cultura visual. Barcelona: Octaedro.

López-Fernández, M. (1991-1992). Arte, feminismo y posmodernidad: Apuntes de lo que viene. Arte, individuo y sociedad, 4, 103-120. Recuperado de http://revistas.ucm.es/index.php/ ARIS/article/view/ARIS9192110103A/6036

Martínez-Collado, A. (2014). Arte contemporáneo, violencia y creación feminista. "Lo personal es político" y la transformación del arte contemporáneo. Dossiers Feministes, 18, 35-54. Recuperado de http://www.e-revistes.uji.es/index.php/dossiers/article/view/1232/1249

Montenegro, C. (2015). Del saber de las mujeres machi al saber docente: Una investigación biográfico-narrativa (Tesis doctoral). Universidad de Barcelona, Barcelona. Recuperado de http://diposit.ub.edu/dspace/handle/2445/66968

Montenegro, C. (2017). Cultura visual y pedagogías feministas: Repensando los espacios educativos. En E. Aberasturi-Apraiz, A. Arriaga e I. Marcellán-Baraze (Coords.), Arte, ilustración y cultura visual. Diálogos en torno a la mediación educativa crítica dentro y fuera de la escuela (pp. 411-416). Bilbao: Servicio Editorial de la Universidad del País Vasco. Recuperado de https://congresoarteilustracion.org/wp-content/uploads/2018/04/libroarte-ilustracion-cultura-visual-congreso-2017-dialogos-mediacion-educativa-criticaescuela.pdf\#page $=6 \& z 00 \mathrm{~m}=$ auto, $-14,569$ 
doi: http://doi.org/10.15359/ree.24-1.23

URL: http://www.una.ac.cr/educare

CORREO: educare@una.cr

Nochlin, L. (1971). Why have there been no great women artists. En V. Gornick y B. K. Moran (Eds.), Woman in sexist society: Studies in power and powerlessness (pp. 480-510). New York: Basic Books.

Observatorio de Equidad de Género en Salud (OEFS). (2013). Informe monográfico 2007-2012. Violenciadegéneroen Chile. Santiago:OPS/OMS. Recuperado dehttps://www.paho.org/chi/ index.php?option=com docman\&view=download\&alias=123-violencia-de-genero-enchile-informe-monografico-2007-2012\&category slug=sistema-de-salud\&ltemid=1145

Ochoa, L. M. (2008). El sueño y la práctica de sí. Pedagogía feminista: Una propuesta. El México: Colegio de México.

Piussi, A. M. (2000). Partir de sí:Nnecesidad y deseo. DUODA Revista d'Estudis Feministes, 19, 107126. Recuperado de https://www.raco.cat/index.php/DUODA/article/view/62649/90712

Red Chilena contra la Violencia Doméstica y Sexual.(2016).Mujeres y violencia:Silenciosy resistencias. Santiago: Autor. Recuperado de http://www.nomasviolenciacontramujeres.cl/wp-content/ uploads/2015/11/mujeres y violencia silencios y resistencia.compressed.pdf

Reilly, M. (Ed.). (2015). Women artists: The Linda Nochlin Reade. Nueva York: Thames \& Hudson.

Rivera, M.-M. (2001). Mujeres en relación: Feminismo 1970-2000. Barcelona: Icaria.

Sáez, F. (2015). Resistencia y dolor. Tracey Emin: La belleza de lo pecaminoso y la fragilidad de lo vulnerable. Barcelona, Research, Art, Creation, 3(1), 13-32. Recuperado de http://dx.doi. org/10.4471/brac.2015.02

Valdivieso, M. (1994). El autorretrato femenino en la historia de Occidente. En M. Vilanova (Comp.), Pensarlas diferencias (pp.97-124). Barcelona: Edición del Seminario Interdisciplinar Mujeres y Sociedad. Recuperado de http://bdigital.unal.edu.co/47756/1/8447703215.pdf

Velasco, S. (2015). Diez enclaves para apuntar al mundo. En A. Collados y J. Rodrigo (Eds.), Transductores 3. Prácticas artísticas en contexto. Itinerarios, útiles y estrategias (pp. 129-146). Granada: Centro José Guerrero.

Villegas, G. (Junio, 2019). Colectivo las profanas. Mujeres artistas en Xalapa. Ponencia presentada en IV Coloquio de Investigación en Gestión Cultural. Universidad Veracruzana, México. Recuperado de https://gestionculturaluv.files.wordpress.com/2013/06/colectivo las profanas - gladys villegas.pdf 